\title{
Should obesity be associated with worse urinary continence outcomes after robotic-assisted radical prostatectomy? a propensity score matching analysis
}

Thiago Camelo Mourão ${ }^{1,2}$, Renato Almeida Rosa de Oliveira ${ }^{1}$, Ricardo de Lima Favaretto ${ }^{1}$, Thiago Borges Marques Santana ${ }^{1,3}$, Carlos Alberto Ricetto Sacomani ${ }^{3}$, Wilson Bachega Jr. ${ }^{3}$, Gustavo Cardoso Guimarães ${ }^{4}$, Stênio de Cássio Zequi ${ }^{3}$

${ }^{1}$ Departamento de Uro-Oncologia, Hospital da Beneficência Portuguesa de São Paulo, São Paulo, SP, Brasil; ${ }^{2}$ Escola de Pós-Graduação, Fundação Antônio Prudente, AC Camargo Cancer Center, São Paulo, SP, Brasil; ${ }^{3}$ Divisão de Urologia, AC Camargo Cancer Center, São Paulo SP, Brasil; ${ }^{4}$ Departamento de Oncologia Cirúrgica, Hospital da Beneficência Portuguesa de São Paulo, SP, Brasil

\section{ABSTRACT}

Purpose: To analyze the association between obesity and urinary incontinence rate in men submitted to robot-assisted radical prostatectomy (RARP) in a high-volume cancer center.

Materials and Methods: We reported 1.077 men who underwent RARP as the primary treatment for localized prostate cancer from 2013 to 2017. Patients were classified as non-obese (normal BMI or overweight) or obese men (BMI $\geq 30 \mathrm{~kg} / \mathrm{m}^{2}$ ). They were grouped according to the age, PSA level, D'Amico risk group, Gleason score, ASA classification, pathological stage, prostate volume, salvage/adjuvant radiotherapy, perioperative complications, and follow-up time. Urinary continence was defined as the use of no pads. For the analysis of long-term urinary continence recovery, we conducted a 1:1 propensity-score matching to control confounders. Results: Among the obese patients, mean BMI was $32.8 \mathrm{~kg} / \mathrm{m}^{2}$, ranging $30-45.7 \mathrm{~kg} / \mathrm{m}^{2}$. Only $2 \%$ was morbidly obese. Obese presented more comorbidities and larger prostates. Median follow-up time was 15 months for the obese. Complications classified as Clavien $\geq 3$ were reported in 5.6\% of the obese and in $4.4 \%$ of the non-obese men ( $p=0.423)$. Median time for continence recovery was 4 months in both groups. In this analysis, HR was 0.989 for urinary continence recovery in obese $(95 \% \mathrm{CI}=0.789-1.240 ; p=0.927)$. Conclusions: Obese can safely undergo RARP with similar continence outcomes comparing to the non-obese men when performed by surgeons with a standardized operative technique. Future studies should perform a subgroup analysis regarding the association of obesity with other comorbidities, intending to optimize patient counseling.

\section{ARTICLE INFO}

Thiago Camelo Mourão

http://orcid.org/0000-0003-4800-6009

Keywords:

Obesity; Urinary Tract; Robotic

Surgical Procedures

Int Braz J Urol. 2022; 48: 122-30

Submitted for publication:

June 07, 2021

Accepted after revision:

July 14, 2021

Published as Ahead of Print: August 10, 2021

\section{INTRODUCTION}

According to the World Health Organization (WHO), there were 1.9 billion overweight adults in the World in 2016, rising almost threefold since the 70s. In Brazil, the WHO estimated an increased age-standardized rate of obesity (body mass index $[\mathrm{BMI}] \geq 30 \mathrm{~kg} / \mathrm{m}^{2}$ ) from $5.2 \%$ in 1975 
to $22.1 \%$ in 2016 . This high prevalence is translated into a common situation among urological patients.

In the literature, some studies have suggested an association between obesity and high-grade prostate cancer $(\mathrm{PCa})(1,2)$. The REDUCE study showed an increased risk of 28\% in a multivariable analysis associated with high-grade $\mathrm{PCa}$ and a lower risk associated with low-grade PCa (3).

Obese patients treated with radical prostatectomy have conflicting results related to functional outcomes. According to some studies, the rates of postoperative urinary incontinence (UI) vary among different techniques (open, laparoscopic, or robot-assisted) (4-8). After the spread of robot-assisted radical prostatectomy (RARP), urological surgeons seem to be more confident about the functional outcomes of obese patients.

This study aimed to analyze a cohort of patients who underwent RARP at a high-volume cancer center and compare the rates of the postoperative recovery of urinary continence between obese men and a propensity score-matched group of non-obese patients.

\section{MATERIALS AND METHODS}

Patient selection and study design

We collected the data from 1.088 patients who underwent RARP as the primary treatment of PCa from May 2013 to December 2017 in a single reference cancer center. The authors collected the data from the preoperative and postoperative appointments described in the patient charts and their respective pathological reports. Figure- 1 shows the flowchart of the study.

In this cohort, the procedures from 13 urological surgeons were included after the completion of their training. Between 2013 and 2014, the patients underwent a transperitoneal RARP technique, including the incision of the endopelvic fascia and the dorsal venous complex control with hemostatic suture. Thereafter, all the patients underwent an extraperitoneal RARP procedure with the complete preservation of the anterior periprostatic tissue (9).
The patients were diagnosed with $\mathrm{PCa}$ by transrectal ultrasound-guided prostate biopsy at a minimum of six weeks before the surgery. For oncological staging, multiparametric magnetic resonance imaging (mpMRI) was performed in all patients. Furthermore, bone or PSMA-PET/CT scans were performed at the discretion of each surgeon in selected patients. Metastatic patients were excluded from this analysis.

The demographic, clinical, and pathological data were collected to compare the groups according to the BMI classification. Normal BMI was determined in patients with a value greater than or equal to 18.5 to $24.9 \mathrm{~kg} / \mathrm{m}^{2}$. Patients with a BMI greater than or equal to 25 to $29.9 \mathrm{~kg} / \mathrm{m}^{2}$ were regarded as overweight, while patients with a BMI greater than or equal to $30 \mathrm{~kg} / \mathrm{m}^{2}$ were considered as obese. Other grouped data were age, serum PSA level, D'Amico risk group, Gleason score, American Society of Anesthesiologists (ASA) risk classification, pathological tumor stage (pT), and follow-up time. Prostate volume was measured by the mpMRI, and salvage or adjuvant radiotherapy was indicated for locoregional or biochemical recurrences.

Routinely, the urinary catheter was removed seven days after the surgery, and the postoperative follow-up was conducted within 15 days, for one month, and then quarterly. Urinary continence was defined as the use of no pads, and continence status was determined through direct patient interviews during the postoperative appointments. The patients who complained of UI were referred to a pelvic floor rehabilitation after the first postoperative month. All the perioperative complications were graded according to the modified Clavien-Dindo classification. The study obtained Institutional Review Board approval.

\section{Statistical analysis}

The data were summarized with medians and interquartile ranges (IQR) for nonparametric continuous variables. The categorical variables were presented as absolute numbers and percentages. Moreover, the Kruskal-Wallis test was used for the analysis of the nonparametric variables. The Fisher exact test or the Pearson chi-squared test was also employed for categorical variables 
Figure 1 - Flowchart of the study.

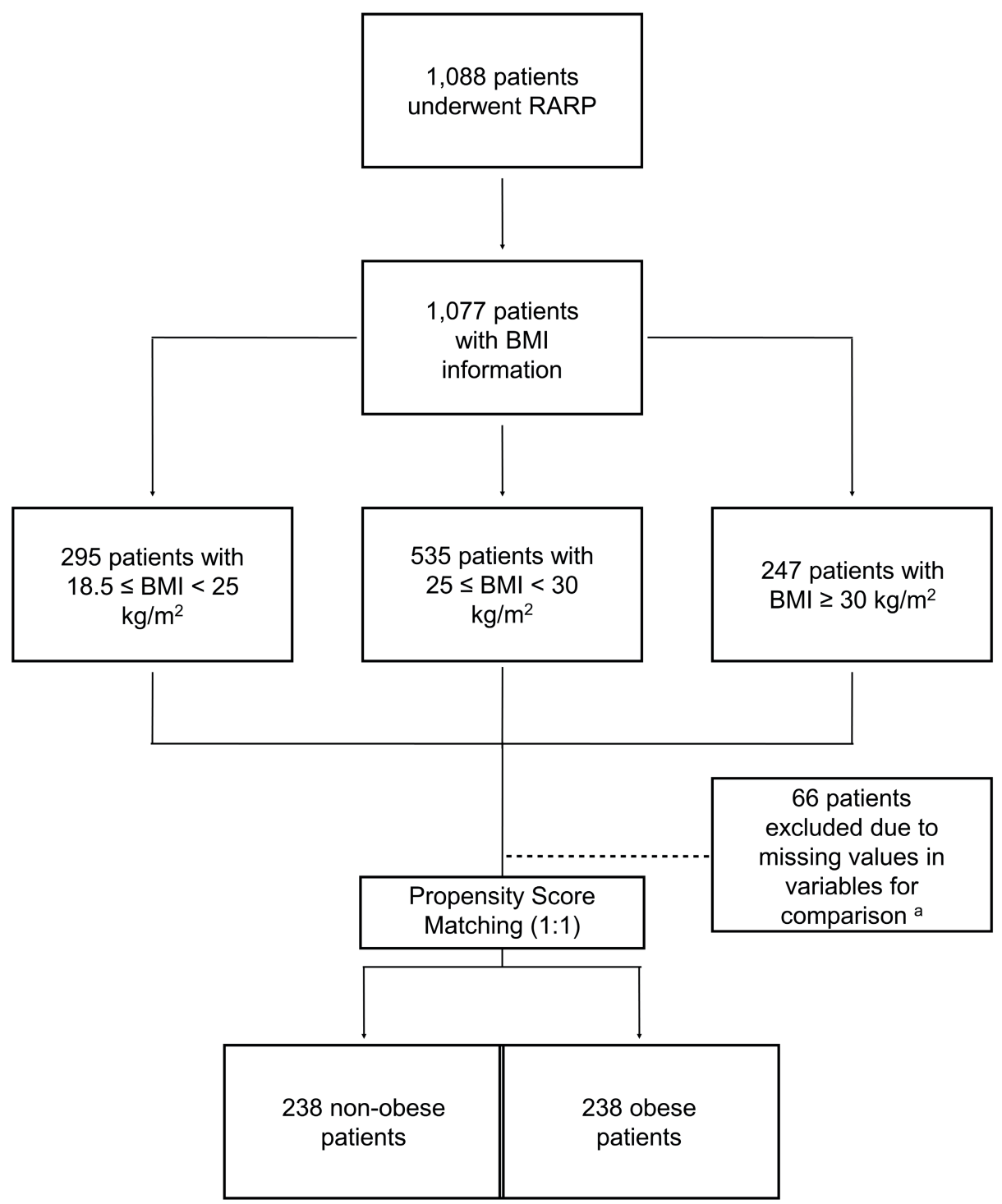

a Variables included in the propensity score matching model: age, prostate volume, pathological stage, American Society of Anesthesiologists (ASA) classification, and surgical technique.

when appropriate. A 1:1 propensity score matching (PSM) approach was utilized to control the confounders for the analysis of the urinary continence recovery. In addition, PSM was calculated by logistic regression. The nearest-neighbor matching model was based on age, prostate volume, pT stage, ASA risk classification, and surgical technique. The missing values of these variables were excluded before the analysis (Figure-1). The Kaplan-Meier method and the Cox proportional hazard model were used for the analysis, and the groups were compared by employing the log-rank test. Additionally, we considered the time zero as the date of the surgery, and the significance level was established for $\mathrm{P}$-value $<0.05$. Statistical analysis was performed using IBM SPSS Statistics version 23.0 (IBM Corp., Armonk, NY) and R software version 4.0.0 (10). A supplementary table was included with data from the patients after the PSM method. 


\section{RESULTS}

Table-1 presents the baseline demographic, clinical, and pathological data for the 1.077 patients grouped by the BMI classification. Almost half of the cohort (49.7\%) were overweight patients. Among the obese patients (247 patients), the mean BMI was $32.8 \mathrm{~kg} / \mathrm{m}^{2}$, ranging from 30.0 to $45.7 \mathrm{~kg} / \mathrm{m}^{2}$. The majority of the obese patients were classified as class I obese, and only $2 \%$ were considered morbidly obese (BMI $\left.\geq 40 \mathrm{~kg} / \mathrm{m}^{2}\right)$.

Significant differences among the groups were evidenced for prostate volume and ASA classification. The obese patients presented with larger

Table 1 - Overall demographic, clinical, and pathological data according BMI classification.

\begin{tabular}{|c|c|c|c|c|}
\hline \multirow{2}{*}{ N (Total = 1077) } & Normal BMI & Overweight & Obese & $P$ - value \\
\hline & $295(27.4 \%)$ & $535(49.7 \%)$ & $247(22.9 \%)$ & \\
\hline Median age (IQR) & $62(57-68)$ & $61(56-67)$ & $61(57-66)$ & $0.173^{a}$ \\
\hline PSA value $(\mathrm{ng} / \mathrm{mL})$ & $\begin{array}{c}5.4(4.0-7.84) \\
N=262\end{array}$ & $\begin{array}{c}5.47(4.01-7.75) \\
N=484\end{array}$ & $\begin{array}{c}5.53(4.01-8.4) \\
N=221\end{array}$ & $0.764^{a}$ \\
\hline Gleason score & & & & $0.261^{b}$ \\
\hline$\leq 6$ & $34(11.6 \%)$ & $59(11.1 \%)$ & $24(9.7 \%)$ & \\
\hline 7 & $216(74 \%)$ & 376 (70.9\%) & $169(68.4 \%)$ & \\
\hline $8-10$ & $42(14.4 \%)$ & 95 (17.9\%) & $54(21.9 \%)$ & \\
\hline D’Amico Risk group & & & & $0.277^{b}$ \\
\hline Low Risk & $103(38.6 \%)$ & $164(33.3 \%)$ & $74(33.9 \%)$ & \\
\hline Intermediate Risk & $84(31.5 \%)$ & $176(35.7 \%)$ & 65 (29.8\%) & \\
\hline High Risk & $80(30 \%)$ & $153(31 \%)$ & 79 (36.2\%) & \\
\hline ASA classification & & & & $<0.001^{b}$ \\
\hline I & $61(20.7 \%)$ & $81(15.2 \%)$ & $11(4.5 \%)$ & \\
\hline ॥ & $213(72.2 \%)$ & $406(76.3 \%)$ & $204(82.6 \%)$ & \\
\hline III & $21(7.1 \%)$ & 45 (8.5\%) & $32(13 \%)$ & \\
\hline Prostate volume $\left(\mathrm{cm}^{3}\right)$ & $\begin{array}{c}39(30-48) \\
N=277\end{array}$ & $\begin{array}{c}41(34-51) \\
N=499\end{array}$ & $\begin{array}{c}42(34-54) \\
N=238\end{array}$ & $0.005^{a}$ \\
\hline Pathological stage & & & & $0.327^{b}$ \\
\hline pT2 & $226(77.7 \%)$ & $397(75 \%)$ & $178(72.1 \%)$ & \\
\hline pT3 & $65(22.3 \%)$ & $132(25 \%)$ & $69(27.9 \%)$ & \\
\hline Median F-U (months) & $13(6-27)$ & $15(6-27)$ & $15(6-28)$ & $0.824^{a}$ \\
\hline Salvage or Adjuvant RT & & & & $0.937^{b}$ \\
\hline Yes & $24(12.7 \%)$ & $43(12 \%)$ & $21(13.1 \%)$ & \\
\hline No & 165 (87.3\%) & 314 (88\%) & 139 (86.9\%) & \\
\hline
\end{tabular}

BMI - Body mass index; PSA - Prostate-specific antigen; ASA - American Society of Anesthesiologists; F-U - Follow-up; RT - Radiotherapy a Kruskal-Wallis test

b $\chi^{2}$ test 
prostates. Prostates over $80 \mathrm{~cm} 3$ were observed in $6.3 \%$ (15 cases) of the obese patients and in 2.7\% (21 cases) of the non-obese patients. As expected, the obese patients presented with a higher frequency of concurrent comorbidities (patients classified as ASA II or ASA III). This is correlated with more comorbidities among obese patients and in more severe systemic diseases within this group.

In this cohort, the other analyzed variables did not display significant differences among patients with normal BMI, overweight patients, and obese patients. Related to the postoperative follow-up period, 57.6\% (132 cases) and 35.8\% (82 cases) of the obese patients had a minimum of 12 months and 24 months of follow-up, respectively. The non-obese patients presented at least 12 months and 24 months of follow-up in 58.6\% (446) and 33.7\% (257) of the cases, respectively.

Perioperative complications were also reported, and they were classified according to the Clavien-Dindo classification in Table-2. There were no significant differences between the obese and non-obese patients $(\mathrm{p}=0.423)$. Complications classified as Clavien $\geq 3$ were reported in $5.6 \%$ of the obese patients and in $4.4 \%$ of the non-obese patients.

The patients were categorized into two groups, namely, non-obese patients and obese patients, after the matching method. Non-obese patients included all cases with calculated BMI $<30 \mathrm{~kg} / \mathrm{m}^{2}$. Figure-2 illustrates the cumulative uri- nary continence recovery between both groups. The median time for continence recovery was 4 months in both groups. In this cohort, there were no significant differences during the follow-up time $(\mathrm{p}=0.92)$. The Cox proportional hazard model was also assessed, and in this analysis, HR was 0.989 for urinary continence recovery in obese men (95\% CI=0.789-1.240; $\mathrm{p}=0.927$ ). Finally, it was conducted an analysis among the whole group of obese patients before the PSM approach. Obese men with localized disease presented a mean time for continence recovery of 4.63 months (3.65 - 5.61 months). In obese men with locally advanced disease, the mean time was 7.11 months (4.84 - 9.38 months). Regarding this comparison, it was evidenced a significant difference $(p=0.040)$.

\section{DISCUSSION}

Concerns associated with functional outcomes are still prevalent in the robotic setting. Frequently, surgeons overcoming their learning curve or in high-volume centers face patients with potentially adverse risk factors and poor functional or oncological outcomes. Even with the lack of high-level evidence, previous randomized trials are clear to show better perioperative outcomes and have provided support to confirm at least the comparable functional outcomes of RARP compared with laparoscopic or open approaches $(11,12)$. The overall prevalence of UI after RARP has been

Table 2 - Comparison of overall perioperative complications for obese (BMI $\left.\geq 30 \mathrm{~kg} / \mathrm{m}^{2}\right)$ and non-obese men (BMI< $\left.30 \mathrm{~kg} / \mathrm{m}^{2}\right)$.

\begin{tabular}{cccc}
\hline Clavien-Dindo classification & Non-obese & Obese & P - value \\
\hline I & $42(5.1 \%)$ & $12(4.9 \%)$ & \\
II & $42(5.1 \%)$ & $20(8.1 \%)$ & \\
IIIA & $13(1.6 \%)$ & $8(3.2 \%)$ & \\
IIIB & $11(1.3 \%)$ & $3(1.2 \%)$ & $0.423^{\text {a }}$ \\
IVA & $10(1.2 \%)$ & $3(1.2 \%)$ & \\
IVB & $1(0.1 \%)$ & 0 & \\
V & $2(0.2 \%)$ & 0 & \\
\hline
\end{tabular}

BMI - Body mass index

a Two-sided Fisher's exact test 
Figure 2 - Kaplan-Meier curve of cumulative continence recovery rate between obese and non-obese patients.

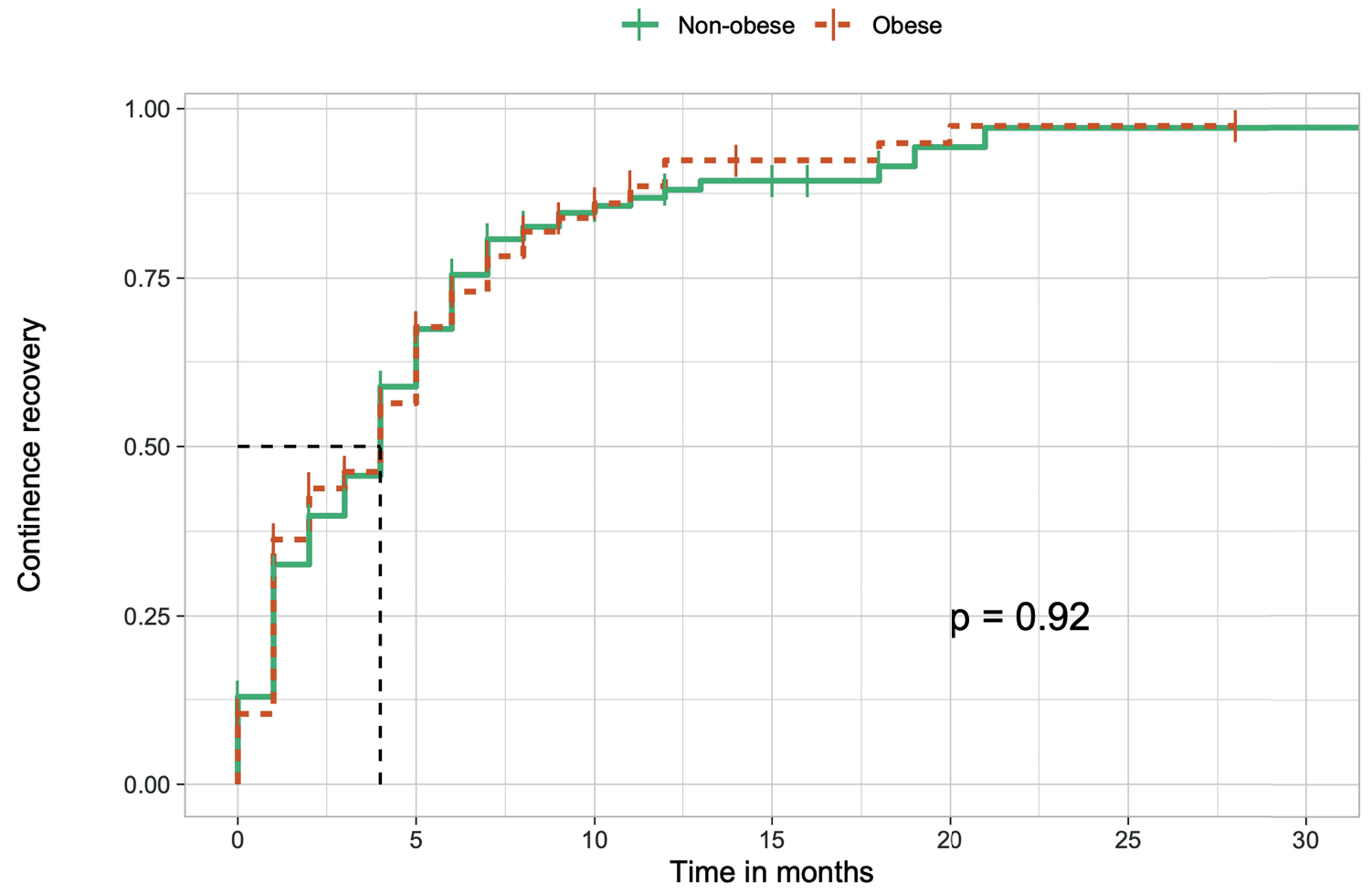

Number at risk

\begin{tabular}{|c|c|c|c|c|c|c|c|c|}
\hline \multirow{2}{*}{ Non-obese } & 209 & 63 & 15 & 8 & 2 & 1 & 1 \\
\hline
\end{tabular}

reported to be ranging from $4 \%$ to $31 \%$ (13), while the 12-month UI rate in obese has been reported to be ranging from $6 \%$ to $47 \%(8,14-16)$.

Over the years, obese men have demonstrated a higher chance to undergo radiotherapy or brachytherapy, as a primary treatment, rather than radical prostatectomy. This has been evidenced by a study with patients from the CaPSURE database (17). Despite that, using a health-related quality-of-life questionnaire, an earlier study extracted from the same database has reported that there are worse urinary functions and bother among patients with a BMI of over $35 \mathrm{~kg} / \mathrm{m}^{2}$ (18).

A meta-analysis published in 2018 showed divergent results about postoperative UI. Two stu- dies involving RARP and other two studies involving laparoscopic radical prostatectomy (LRP) were evaluated. The authors evidenced a significant association between obesity and UI at 12 months in the patients who underwent RARP $(\mathrm{OR}=2.43$, 95\% $\mathrm{CI}=1.21-4.88)$ and at 24 months $(\mathrm{OR}=2.00$, $95 \% \mathrm{CI}=1.57-2.56)$. However, the patients who underwent LRP did not show this association (4). Probably, this significantly better continence rate in non-obese men occurred due to the study of Wiltz et al. (15), which constituted $90 \%$ of the men who underwent RARP in the previously mentioned meta-analysis and exhibited similar conclusions.

In fact, considering studies prior to 2010, Boorjian et al. suggested that RARP offers simi- 
lar functional outcomes for obese men (16). Other investigations have reported poorer postoperative continence rates or a longer time to continence recovery in obese men than in non-obese men (6, $14,15)$. Analyzing more recent studies, we can come across with more authors affirming that there is no significant association between obesity and long-term UI rate $(7,8,19)$. The study of Kumar et al. validated that the only significant divergence is about an earlier median time to continence recovery (19). Some possible explanations are that reference centers have achieved a higher expertise level over this period and that several technical improvements have been reported. Other discrepancies may occur due to the different techniques and continence definitions. A local study published in 2019 reported data from 104 consecutive RARP. In this series, only 16 patients were obese and there was no statistical difference in continence recovery compared to the non-obese men. However, the mean time to reach urinary continence was higher for the obese patients (5.08 months vs. 2.71 months) (20).

Considering morbid obesity, only a few studies have included this particular population, but none of them have reported functional outcomes over the follow-up period (21-23). In our study, it was evidenced a non-significant difference among class I to II obese and class III obese men (data not reported). Nonetheless, there are only 2\% of morbidly obese patients in our cohort.

Several limitations can be discussed in this study. A debatable fact is that the group is composed of different surgeons in a single cancer center, who may have distinct surgical skills. Despite that, surgeons involved in this study overcame their learning curve with a standardized protocol and similar methods. They were included at the robotic program after assisting cases as bedside surgeons (24), completing the training on da Vinci system, and after approval of the head of the department. Some of them have a huge previous experience in open procedures. Others have been laparoscopists before the beginning of their learning curves with robotics. Additionally, findings are limited by the retrospective nature of the study and by the missing values in some cases, requiring exclusion for the PSM analysis. Despite that, we could control some confounders between both groups with matched analysis and compare them for an adequate follow-up period. Furtherly, we were not able to list the frequency of each one of the concurrent comorbidities in obese and non-obese men, which could be associated with worse UI status in particular scenarios. There are other potential conflictual covariates, such as race, educational level, or sedentary lifestyle, that could lead to divergent results. Another point is that only $2 \%$ of the cases consisted of morbidly obese, besides that super obese patients (BMI $\geq 50 \mathrm{~kg} / \mathrm{m}^{2}$ ) were not reported. Future studies with this specific population could lead to divergent outcomes. Finally, to our knowledge, this is largest national study analyzing the urinary functional outcomes in the population of obese men who underwent RARP.

\section{CONCLUSIONS}

Obese patients can safely undergo robotic-assisted radical prostatectomy with similar continence outcomes compared with non-obese men. Our results suggest a comparable perioperative complication rate between the groups when performed by surgeons with a standardized operative technique. Future studies should perform a subgroup analysis regarding the association of obesity with other comorbidities, intending to optimize patient counseling.

\section{CONFLICT OF INTEREST}

None declared.

\section{REFERENCES}

1. Zhang X, Zhou G, Sun B, Zhao G, Liu D, Sun J, et al. Impact of obesity upon prostate cancer-associated mortality: A metaanalysis of 17 cohort studies. Oncol Lett. 2015; 9:1307-12.

2. Hu X, Hu C, Zhang C, Zhang M, Long S, Cao Z. Role of Adiponectin in prostate cancer. Int Braz J Urol. 2019; 45:220-8.

3. Vidal AC, Howard LE, Moreira DM, Castro-Santamaria R, Andriole GL Jr, Freedland SJ. Obesity increases the risk for high-grade prostate cancer: results from the REDUCE study. Cancer Epidemiol Biomarkers Prev. 2014; 23:2936-42. 
4. Wei Y, Wu YP, Lin MY, Chen SH, Lin YZ, Li XD, et al. Impact of Obesity on Long-Term Urinary Incontinence after Radical Prostatectomy: A Meta-Analysis. Biomed Res Int. 2018; 2018:8279523.

5. Xu T, Wang X, Xia L, Zhang X, Qin L, Zhong S, et al. Robotassisted prostatectomy in obese patients: how influential is obesity on operative outcomes? J Endourol. 2015; 29:198-208.

6. van Roermund JG, van Basten JP, Kiemeney LA, Karthaus HF, Witjes JA. Impact of obesity on surgical outcomes following open radical prostatectomy. Urol Int. 2009; 82:256-61.

7. Garg T, Young AJ, Kost KA, Park AM, Danella JF, Kirchner HL. Patient-reported quality of life recovery curves after robotic prostatectomy are similar across body mass index categories. Investig Clin Urol. 2017; 58:331-8.

8. Gu X, Araki M, Wong C. Does elevated body mass index (BMI) affect the clinical outcomes of robot-assisted laparoscopic prostatectomy (RALP): a prospective cohort study. Int $\mathrm{J}$ Surg. 2014; 12:1055-60.

9. Guimarães GC, Oliveira RAR, Santana TBM, Favaretto RL, Mourão TC, Rocha MM, et al. Comparative Analysis of Functional Outcomes Between Two Different Techniques After 1088 Robotic-Assisted Radical Prostatectomies in a High-Volume Cancer Center: A Clipless Approach. J Endourol. 2019; 33:1017-24.

10. R Core Team. The R Project for Statistical Computing. 2018. [Internet]. Available at. <https://www.r-project.org/>

11. Porpiglia F, Morra I, Lucci Chiarissi M, Manfredi M, Mele F, Grande S, et al. Randomised controlled trial comparing laparoscopic and robot-assisted radical prostatectomy. Eur Urol. 2013; 63:606-14.

12. Coughlin GD, Yaxley JW, Chambers SK, Occhipinti S, Samaratunga $\mathrm{H}$, Zajdlewicz L, et al. Teloken P, Dunglison N, Williams S, Lavin MF, Gardiner RA. Robot-assisted laparoscopic prostatectomy versus open radical retropubic prostatectomy: 24-month outcomes from a randomised controlled study. Lancet Oncol. 2018; 19:1051-60.

13. Ficarra V, Novara G, Rosen RC, Artibani W, Carroll PR, Costello A, et al. Systematic review and meta-analysis of studies reporting urinary continence recovery after robotassisted radical prostatectomy. Eur Urol. 2012; 62:405-17.

14. Ahlering TE, Eichel L, Edwards R, Skarecky DW. Impact of obesity on clinical outcomes in robotic prostatectomy. Urology. 2005; 65:740-4.

15. Wiltz AL, Shikanov S, Eggener SE, Katz MH, Thong AE, Steinberg GD, et al. Robotic radical prostatectomy in overweight and obese patients: oncological and validatedfunctional outcomes. Urology. 2009; 73:316-22.
16. Boorjian SA, Crispen PL, Carlson RE, Rangel LJ, Karnes RJ, Frank I, et al. Impact of obesity on clinicopathologic outcomes after robot-assisted laparoscopic prostatectomy. J Endourol. 2008; 22:1471-6.

17. Davies BJ, Walsh TJ, Ross PL, Knight SJ, Sadetsky N, Carroll PR, et al. Effect of BMI on primary treatment of prostate cancer. Urology. 2008; 72:406-11.

18. Anast JW, Sadetsky N, Pasta DJ, Bassett WW, Latini D, DuChane J, et al. The impact of obesity on health related quality of life before and after radical prostatectomy (data from CaPSURE). J Urol. 2005; 173:1132-8.

19. Kumar A, Samavedi S, Bates AS, Coelho RF, Rocco B, Palmer $\mathrm{K}$, et al. Continence outcomes of robot-assisted radical prostatectomy in patients with adverse urinary continence risk factors. BJU Int. 2015; 116:764-70.

20. Neumaier MF, Segall CH Júnior, Hisano M, Rocha FET, Arap S, Arap MA. Factors affecting urinary continence and sexual potency recovery after robotic-assisted radical prostatectomy. Int Braz J Urol. 2019; 45:703-12.

21. Agrawal V, Feng C, Joseph J. Outcomes of Extraperitoneal Robot-Assisted Radical Prostatectomy in the Morbidly Obese: A Propensity Score-Matched Study. J Endourol. 2015; 29:677-82.

22. Yates J, Munver R, Sawczuk I. Robot-assisted laparoscopic radical prostatectomy in the morbidly obese patient. Prostate Cancer. 2011; 2011:618623.

23. Abdul-Muhsin H, Giedelman C, Samavedi S, Schatloff 0 , Coelho R, Rocco B, et al. Perioperative and early oncological outcomes after robot-assisted radical prostatectomy (RARP) in morbidly obese patients: a propensity scorematched study. BJU Int. 2014; 113:84-91.

24. Cimen HI, Atik YT, Gul D, Uysal B, Balbay MD. Serving as a bedside surgeon before performing robotic radical prostatectomy improves surgical outcomes. Int Braz J Urol. 2019; 45:1122-8.

Correspondence address:

Thiago Camelo Mourão, MD

Rua Dona Adma Jafet, 74/ 151

Bela Vista, São Paulo, SP, 01308-050, Brasil

Telephone. + 5511 3259-3433

E-mail: thiagocmourao@gmail.com 
APPENDIX

Supplementary Table - Data from obese and non-obese men included in the study after a propensity score matching approach.

\begin{tabular}{|c|c|c|c|c|c|c|c|c|c|c|}
\hline ID case & Age & Weight & Height & BMI & $\begin{array}{c}\text { Prostate } \\
\text { volume }\end{array}$ & $\begin{array}{l}\text { ISUP } \\
\text { grade }\end{array}$ & PSA level & $\begin{array}{c}\text { D'Amico } \\
\text { classification }\end{array}$ & $\begin{array}{c}\text { ASA } \\
\text { classification }\end{array}$ & pT stage \\
\hline 1 & 62 & 103,0 & 1,820 & 31,10 & 59,0 & 2 & 9,25 & Intermediate risk & 2 & pT2c \\
\hline 2 & 41 & 82,0 & 1,700 & 28,37 & 23,0 & 3 & 3,65 & High risk & 1 & pT2c \\
\hline 3 & 58 & 92,0 & 1,720 & 31,10 & 47,0 & 1 & 6,78 & Low risk & 2 & pT2c \\
\hline 4 & 54 & 95,0 & 1,720 & 32,11 & 40,0 & 1 & 5,54 & Low risk & 2 & pT2c \\
\hline 5 & 65 & 82,0 & 1,600 & 32,03 & 42,0 & 3 & 8,15 & High risk & 2 & $\mathrm{pT} 2 \mathrm{c}$ \\
\hline 6 & 63 & 76,0 & 1,590 & 30,06 & 98,0 & 2 & 12,25 & Intermediate risk & 2 & $\mathrm{pT} 2 \mathrm{c}$ \\
\hline 7 & 63 & 120,0 & 1,750 & 39,18 & 37,0 & 1 & 5,78 & Low risk & 3 & $\mathrm{pT} 2 \mathrm{c}$ \\
\hline 8 & 56 & 102,0 & 1,900 & 28,25 & 50,0 & 1 & 11,00 & High risk & 3 & $\mathrm{pT} 2 \mathrm{c}$ \\
\hline 9 & 61 & 89,0 & 1,710 & 30,44 & 38,0 & 1 & 4,72 & Low risk & 2 & $\mathrm{pT} 2 \mathrm{c}$ \\
\hline 10 & 69 & 80,0 & 1,590 & 31,64 & 33,0 & 2 & 16,00 & High risk & 3 & pT3a \\
\hline 11 & 75 & 93,0 & 1,730 & 31,07 & 60,0 & 4 & 5,20 & High risk & 2 & $\mathrm{pT} 3 \mathrm{a}$ \\
\hline 12 & 60 & 105,0 & 1,800 & 32,41 & 42,0 & 1 & 11,00 & Low risk & 2 & $\mathrm{pT} 2 \mathrm{c}$ \\
\hline 13 & 69 & 90,0 & 1,860 & 26,01 & 52,0 & 3 & 5,39 & High risk & 3 & pT3b \\
\hline 14 & 60 & 100,0 & 1,720 & 33,80 & 49,0 & 4 & 20,70 & High risk & 2 & $\mathrm{pT} 3 \mathrm{~b}$ \\
\hline 15 & 66 & 85,0 & 1,660 & 30,85 & 30,0 & 5 & 4,41 & High risk & 2 & pT3b \\
\hline 16 & 61 & 120,0 & 1,620 & 45,72 & 49,0 & N/A & N/A & N/A & 2 & $\mathrm{pT} 2 \mathrm{c}$ \\
\hline 17 & 48 & 90,0 & 1,700 & 31,14 & 44,0 & 4 & 0,41 & High risk & 2 & pT3a \\
\hline 18 & 73 & 78,0 & 1,780 & 24,62 & 48,0 & 2 & 1,20 & Intermediate risk & 3 & pT3a \\
\hline 19 & 48 & 123,0 & 1,840 & 36,33 & 32,0 & 2 & 5,09 & Intermediate risk & 2 & pT2c \\
\hline 20 & 72 & 96,0 & 1,790 & 29,96 & 50,0 & N/A & N/A & N/A & 3 & pT2c \\
\hline 21 & 65 & 109,0 & 1,810 & 33,27 & 42,0 & N/A & 1,25 & N/A & 2 & pT3b \\
\hline 22 & 68 & 91,0 & 1,760 & 29,38 & 44,0 & 5 & 62,00 & High risk & 3 & $\mathrm{pT} 2 \mathrm{c}$ \\
\hline 23 & 57 & 70,0 & 1,710 & 23,94 & 54,0 & 1 & 8,40 & Low risk & 2 & pT2c \\
\hline 24 & 65 & 91,0 & 1,630 & 34,25 & 36,0 & 1 & 1,15 & Low risk & 2 & pT3a \\
\hline 25 & 54 & 115,0 & 1,850 & 33,60 & 34,0 & 1 & 4,03 & Low risk & 2 & $\mathrm{pT} 2 \mathrm{c}$ \\
\hline 26 & 71 & 107,0 & 1,810 & 32,66 & 83,0 & 3 & 7,52 & High risk & 2 & $\mathrm{pT} 2 \mathrm{c}$ \\
\hline 27 & 58 & 105,0 & 1,850 & 30,68 & 24,0 & 1 & 3,02 & Low risk & 2 & pT2c \\
\hline 28 & 68 & 73,0 & 1,730 & 24,39 & 72,0 & 1 & 11,90 & Intermediate risk & 2 & $\mathrm{pT} 2 \mathrm{c}$ \\
\hline 29 & 55 & 102,0 & 1,690 & 35,71 & 47,0 & 1 & 3,76 & Low risk & 3 & $\mathrm{pT} 2 \mathrm{c}$ \\
\hline 30 & 67 & 116,0 & 1,860 & 33,53 & 92,0 & 5 & 8,01 & High risk & 2 & pT3b \\
\hline 31 & 61 & 98,0 & 1,790 & 30,59 & 54,0 & 5 & 3,36 & High risk & 2 & $\mathrm{pT} 3 \mathrm{~b}$ \\
\hline 32 & 69 & 90,0 & 1,690 & 31,51 & 61,0 & 5 & 5,30 & High risk & 2 & $\mathrm{pT} 2 \mathrm{c}$ \\
\hline 33 & 62 & 120,0 & 1,760 & 38,74 & 31,0 & 5 & 7,90 & High risk & 2 & $\mathrm{pT} 3 \mathrm{~b}$ \\
\hline 34 & 76 & 90,0 & 1,880 & 25,46 & 37,0 & 2 & 4,46 & Intermediate risk & 3 & $\mathrm{pT} 2 \mathrm{c}$ \\
\hline 35 & 55 & 81,0 & 1,740 & 26,75 & 41,0 & 1 & 5,49 & Low risk & 2 & $\mathrm{pT} 2 \mathrm{c}$ \\
\hline 36 & 69 & 111,0 & 1,800 & 34,26 & 52,0 & 1 & 2,68 & Low risk & 3 & $\mathrm{pT} 2 \mathrm{c}$ \\
\hline 37 & 61 & 94,0 & 1,640 & 34,95 & 54,0 & 2 & 6,50 & Intermediate risk & 2 & pT2c \\
\hline 38 & 61 & 91,0 & 1,670 & 32,63 & 23,0 & 2 & 12,00 & High risk & 2 & $\mathrm{pT} 2 \mathrm{c}$ \\
\hline 39 & 72 & 90,0 & 1,670 & 32,27 & 61,0 & 2 & 18,00 & High risk & 3 & $\mathrm{pT} 3 \mathrm{~b}$ \\
\hline 40 & 60 & 92,0 & 1,650 & 33,79 & 46,0 & 4 & 13,24 & High risk & 1 & pT3b \\
\hline 41 & 72 & 93,0 & 1,720 & 31,44 & 31,0 & 2 & 6,96 & Intermediate risk & 2 & pT2c \\
\hline 42 & 70 & 89,0 & 1,660 & 32,30 & 44,0 & N/A & N/A & N/A & 2 & pT2a \\
\hline
\end{tabular}

